\title{
BMJ Open Seasonal variation in musculoskeletal extremity injuries in school children aged 6-12 followed prospectively over 2.5 years: a cohort study
}

\author{
Eva Jespersen, ${ }^{1}$ René Holst, ${ }^{2}$ Claudia Franz, ${ }^{1}$ Christina T Rexen, ${ }^{1}$ \\ Niels Wedderkopp ${ }^{1,3}$
}

To cite: Jespersen E, Holst R, Franz C, et al. Seasonal variation in musculoskeletal extremity injuries in school children aged 6-12 followed prospectively over 2.5 years: a cohort study. BMJ Open 2014;4:e004165. doi:10.1136/bmjopen-2013004165

- Prepublication history for this paper is available online. To view these files please visit the journal online (http://dx.doi.org/10.1136/ bmjopen-2013-004165).

Received 2 October 2013 Revised 18 November 2013 Accepted 20 November 2013

CrossMark

For numbered affiliations see end of article.

Correspondence to

Eva Jespersen;

ejespersen@health.sdu.dk

\section{ABSTRACT}

Objectives: The type and level of physical activity in children vary over seasons and might thus influence the injury patterns. However, very little information is available on the distribution of injuries over the calendar year. This study aims to describe and analyse the seasonal variation in extremity injuries in children.

Design: Prospective cohort study.

Setting: 10 public schools in the municipality of Svendborg, Denmark.

Participants: A total of 1259 school children aged 6-12 years participating in the Childhood Health, Activity, and Motor Performance School Study Denmark.

Methods: School children were surveyed each week during 2.5 school-years. Musculoskeletal injuries were reported by parents answering automated mobile phone text questions (SMS-Track) on a weekly basis and diagnosed by clinicians. Data were analysed for prevalence and incidence rates over time with adjustments for gender and age.

Results: Injuries in the lower extremities were reported most frequently $(n=1049)$. There was a significant seasonal variation in incidence and prevalence for lower extremity injuries and for lower and upper extremity injuries combined $(n=1229)$. For the upper extremities $(n=180)$, seasonal variation had a significant effect on the risk of prevalence. Analysis showed a $46 \%$ increase in injury incidence and a $32 \%$ increase in injury prevalence during summer relative to winter for lower and upper extremity injuries combined.

Conclusions: There are clear seasonal differences in the occurrence of musculoskeletal extremity injuries among children with almost twice as high injury incidence and prevalence estimates during autumn, summer and spring compared with winter. This suggests further research into the underlying causes for seasonal variation and calls for preventive strategies to be implemented in order to actively prepare and supervise children before and during high-risk periods.

\section{BACKGROUND}

Musculoskeletal problems are common in childhood. ${ }^{12}$ Definite pathological states are

\section{Strengths and limitations of this study}

- The main strength was the frequent, prospective and fine-meshed method of collecting data on injury incidence and prevalence in a populationbased large sample of school children with high participation compliance during 2.5 years.

- A general limitation to the data collection was the lack of information on injuries during 6 weeks of children's summer holidays, thus the descriptive data were presented with the lack of observations during summer holidays, while the modelled data were extrapolated to full annual variation.

uncommon at this age, but various types of injuries can cause pain and disability. Physical activity-related injuries have been established as a leading cause of paediatric injuries in western countries ${ }^{3-5}$ and they constitute a significant public health burden, with high direct and indirect costs for children, parents and society. ${ }^{6} 7$ Injuries sustained in sports activities may cause short-term disability, absence from school, sports and physical activity, and long-term consequences such as osteoarthritis. ${ }^{8-10}$

The most common injuries in school-aged children are ligamentous sprains, contusions, muscle/tendon strains, fractures and different types of overuse injuries, located primarily in lower extremities but also in upper extremities. ${ }^{11-14}$ It seems reasonable that different types of physical activities engender different types of injuries and those different times of the year invite different types and intensities of physical activities.

A review of the literature reveals that very little information is available on the injury pattern in children over the calendar year. Only data on more serious injuries from emergency room treatments and hospitalised children are available and show an indication 
of seasonal pattern in the incidence and type of injuries. ${ }^{15-19}$ The literature on the seasonal injury pattern among children in the general population is scarce, ${ }^{19}$ but is necessary in order to obtain proper incidence and prevalence data including less serious injuries and overuse injuries.

An efficient preventive approach to musculoskeletal injuries in children requires an insight in the circumstances under which they occur. The purpose of this study was to determine the seasonal pattern in extremity injuries in children by following the children during 2.5 consecutive school-years with systematic weekly automated mobile phone text messaging (SMS-Track) and clinical examinations and diagnosing.

\section{METHODS}

The study method has been extensively reported elsewhere $^{20}$ and the relevant aspects are briefly described below.

\section{Study participants}

Children from the preschool to the sixth grades from 10 public schools in the county of Svendborg, Denmark, who participated in a natural experiment (the Childhood Health, Activity, and Motor Performance School Study Denmark, CHAMPS Study-DK) were surveyed weekly during 2.5 school-years. The study consisted of a comparison between sports schools and normal schools and included a total of 1218 children at baseline.

All boys and girls participating in the CHAMPS Study-DK were invited to participate in the registration of musculoskeletal pain and injuries. The study was kept open, with the opportunity for children moving to project schools to enter the study. Owing to the novel data collection method (SMS-Track), the schools were included gradually in order to allow for a phasing-in process.

\section{Data collection from parents}

SMS-Track $^{21}$ is a web-based IT system, developed as a tool for frequent monitoring, complying with Shiffman's principle of Ecological Momentary Assessment. It was used in this study to investigate the fluctuations in musculoskeletal symptoms over time. Every week on Sunday, the parents received the following question: "Has [NAME OF CHILD] during the last week had any pain in: (1) Neck, back or low back; (2) shoulder, arm or hand; (3) hip, leg or foot and (4) no, my child has not had any pain." The parents were asked to type the number in front of the correct answer in a return text message. Data used in this report relate to items 2, 3 and 4.

\section{Quality of the SIMS-Track data}

The returned answers were automatically recorded and inserted into a database. If no response was received or if the answer was inaccurate (eg, a response in words), the responders were contacted by telephone. It was deemed better to use parents as the informants than the child, as self-report questionnaire data from young children may be inaccurate. ${ }^{22}$ Frequent data collection in large cohorts with short recall intervals (in this case 1 week) is well suited to obtain valid information on the periodic dynamics of the injury incidence and prevalence rates over time intervals covered by the study period. Data collection was put at hold during the 6 weeks of summer holidays.

A validation study was undertaken in order to determine the reproducibility of the SMS-Track reporting when comparing it with verbal reporting. The sensitivity for the SMS data was 0.98 , specificity 0.87 , positive predictive value 0.94 and the negative predictive value 0.95 , indicating high validity of the data. ${ }^{23}$

\section{Clinician-generated data}

Parents who reported that their child had pain in the previous week were contacted by telephone at the beginning of the subsequent week by one of the four clinicians. Children, whose symptoms still persisted, were examined by physiotherapists, chiropractors and/or a medical practitioner within the next fortnight.

Injuries were diagnosed according to the International Classification of Diseases, 10th revised edition (ICD-10). ${ }^{24}$ If necessary, the child was referred for further paraclinical examination (such as X-ray, ultrasound or MRI) or to be seen by a medical specialist. Information on children being seen or treated elsewhere (eg, emergency department and GP) during the study period was collected concurrently to get a complete data collection on injuries. Only children with a diagnosed injury were included in the data analysis.

\section{Analysis and presentation of data}

Explorative plots of the observed injury incidence and prevalence rates for all extremity injuries combined over the period of the study indicated an annual pattern peaking during the autumn and spring seasons, reaching a minimum incidence and prevalence rate during wintertime. This suggested a harmonic regression model where the annual variation was accounted for by sine and cosine terms with periods of 52 weeks.

A mixed effect logistic regression model was used to estimate injury incidence and prevalence risk with seasonal variation being of primary interest and represented by the sine and cosine terms. Incidence and prevalence analyses were conducted separately. The incidence models included gender, grade, grade squared and with separate grade effects for the two genders represented by interaction terms. These models were based only on the data from the risk episodes, as a child carries no information on the risk of injury, when being in a state of injury. The prevalence models were based on all data, but allowed for different effects for the states of being at risk and the state of being injured. These 
included gender, grade, grade squared and the current duration for the states of being injured. The latter variable accounted for the serial correlation between consecutive weeks in episodes of injury. Finally, the prevalence models included a state variable to account for the different risks of observing an injury in the two states.

The heterogeneity induced by the hierarchical sampling scheme was handled in a mixed model framework with schools, classes and individuals representing the three levels of random variation.

Potential patterns for the missing values were addressed by a logistic regression analysis controlling for gender, age, school type and leisure time sports effects.

The model-based estimates in tables and figures are presented separately for lower and upper extremity injuries, and also for lower and upper extremity injuries aggregated. Hereafter, these will be termed extremity injuries or extremity injuries combined.

While the descriptive data are presented with the lack of observations during 6 weeks of summer holidays, modelled data will be presented extrapolated to full annual variation.

All analysis was performed using STATA V.12.1 (StataCorp, Texas, USA) and R 2.15.1.25

\section{RESULTS}

\section{Descriptive data}

There was a gradual inclusion of schools starting with 231 children from 3 schools and ending with children from all 10 schools being included 8 months later. In total, 1259 children participated in the study. The range of participation time was 1-113 weeks with an average of 90.2 weeks. New children moving to project schools counterbalanced dropouts due to children moving away from the municipality or changing to a non-project school. Only a small number $(n=15)$ chose to drop out for other reasons, the main one being that answering SMS questions every week was too bothersome. The overall response rate throughout the study period of 113 weeks was $96.2 \%$. A total number of 109245 observations were recorded and 4297 (3.8\%) were missing. Analysis of missing data did not show any patterns when looking at gender, age, school type and leisure time sports.

Table 1 shows the number of injuries by gender and age (grade) of 1259 participating children. A total of 1229 extremity injuries were observed and the overall observed weekly injury incidence and prevalence rates were $1.1 \%$ and $4.6 \%$, respectively.

\section{Seasonal pattern}

There was a clear seasonal variation in the observed incidences of extremity injuries. The highest injury incidence and prevalence rates for extremity injuries were observed for autumn, $1.3 \%$ and $5.1 \%$, respectively, and for spring, $1.2 \%$ and $5 \%$, respectively, whereas they decreased to $0.8 \%$ and $3.6 \%$, respectively, in winter (table 2).

The analysis showed a significant seasonal variation for extremity injuries on incidence and prevalence rates (table 3). Other significant effects on the incidences were gender and grade, with different effects of grade for the two genders. The prevalence rates of extremity injuries showed significant effects of gender, class, the current duration of the injury and a state effect reflecting the difference between the risk and the prevalence states (table 3).

The model-based estimates of the incidence rates reached a maximum of $1 \%$ (girls) and $0.9 \%$ (boys) in week 29.3 (mid-July) and a minimum of $0.7 \%$ (girls) and $0.6 \%$ (boys) in week 3.3 (mid-January). The corresponding estimates for the prevalence rates reached a maximum of $4.5 \%$ (girls) and $3.7 \%$ (boys) in week 26.9 (late June) and a minimum of $3.4 \%$ (girls) and $2.8 \%$ (boys) in week 0.9 (early January).

Figure 1 shows the fitted curves for the seasonal variation for the injury incidence and prevalence for extremity injuries by gender and age with grade level $(0-6)$ as a proxy of age. The corresponding results can be found in figures 2 and 3, but now showing patterns separately for upper and lower extremity injuries.

Table 1 Number of children and number of injuries by gender and age (grade) of 1259 school children followed over 2.5 years

\begin{tabular}{|c|c|c|c|c|c|c|c|}
\hline & Preschool & Grade 1 & Grade 2 & Grade 3 & Grade 4 & Grade 5 & Grade 6 \\
\hline Number & 168 & 415 & 643 & 691 & 696 & 476 & 239 \\
\hline Age (year) & $6-7$ & $7-8$ & $8-9$ & $9-10$ & $10-11$ & $11-12$ & $12-13$ \\
\hline \multicolumn{8}{|l|}{ Gender } \\
\hline Girls & 90 & 222 & 334 & 348 & 360 & 261 & 131 \\
\hline Boys & 78 & 193 & 309 & 343 & 336 & 215 & 108 \\
\hline \multicolumn{8}{|l|}{ Upper extremity injuries } \\
\hline Number of injuries & 2 & 7 & 20 & 37 & 44 & 51 & 19 \\
\hline \multicolumn{8}{|l|}{ Lower extremity injuries } \\
\hline Number of injuries & 9 & 43 & 149 & 243 & 256 & 226 & 123 \\
\hline
\end{tabular}


Table 2 Observed seasonal numbers and injury incidence and prevalence rates of upper extremity injuries, lower extremity injuries and extremity injuries combined diagnosed during 2.5 years

\begin{tabular}{|c|c|c|c|c|c|}
\hline & $\begin{array}{l}\text { Autumn } \\
\text { (September, } \\
\text { October and } \\
\text { November) }\end{array}$ & $\begin{array}{l}\text { Winter } \\
\text { (December, } \\
\text { January and } \\
\text { February) }\end{array}$ & $\begin{array}{l}\text { Spring } \\
\text { (March, April } \\
\text { and May) }\end{array}$ & $\begin{array}{l}\text { Summer* } \\
\text { (June, July } \\
\text { and August) }\end{array}$ & Total \\
\hline \multicolumn{6}{|l|}{ Upper extremity injuries } \\
\hline Number & 57 & 31 & 63 & 29 & 180 \\
\hline Incidence rate in percentage $( \pm S D)$ & $0.2( \pm 4.4)$ & $0.1( \pm 3.2)$ & $0.2( \pm 4.1)$ & $0.2( \pm 4.2)$ & $0.2( \pm 4.0)$ \\
\hline Prevalence rate in percentage $( \pm S D)$ & $0.6( \pm 7.6)$ & $0.3( \pm 5.9)$ & $0.6( \pm 7.7)$ & $0.6( \pm 7.6)$ & $0.5( \pm 7.2)$ \\
\hline \multicolumn{6}{|l|}{ Lower extremity injuries } \\
\hline Number & 322 & 188 & 386 & 153 & 1049 \\
\hline Incidence rate in percentage $( \pm S D)$ & $1.1( \pm 10.6)$ & $0.7( \pm 8.1)$ & $1.0( \pm 10.1)$ & $1.0( \pm 9.8)$ & $1.0( \pm 9.7)$ \\
\hline Prevalence rate in percentage $( \pm S D)$ & $4.6( \pm 20.9)$ & $3.3( \pm 17.9)$ & $4.5( \pm 20.6)$ & $4.1( \pm 19.9)$ & $4.1( \pm 19.9)$ \\
\hline \multicolumn{6}{|l|}{ Extremity injuries combined } \\
\hline Number & 379 & 219 & 449 & 182 & 1229 \\
\hline Incidence rate in percentage $( \pm S D)$ & $1.3( \pm 11.5)$ & $0.8( \pm 10.5)$ & $1.2( \pm 10.9)$ & $1.2( \pm 10.7)$ & $1.1( \pm 10.5)$ \\
\hline Prevalence rate in percentage $( \pm S D)$ & $5.1( \pm 22.1)$ & $3.6( \pm 18.8)$ & $5.0( \pm 21.8)$ & $4.7( \pm 21.1)$ & $4.6( \pm 21.0)$ \\
\hline
\end{tabular}

\section{DISCUSSION}

This is the first prospective study showing a seasonal variation in injuries of the extremities in a cohort of school children followed closely during 2.5 years. The weekly data showed $46 \%$ increase in injury incidence and $32 \%$ increase in injury prevalence during summer compared with winter for extremity injuries.

Table 3 Mixed model analysis presenting factors explaining incidence and prevalence of upper extremity injuries, lower extremity injuries and extremity injuries combined

\begin{tabular}{llll}
\hline & $\begin{array}{c}\text { Upper } \\
\text { extremity } \\
\text { injuries }\end{array}$ & $\begin{array}{l}\text { Lower } \\
\text { extremity } \\
\text { injuries }\end{array}$ & $\begin{array}{l}\text { Extremity } \\
\text { injuries } \\
\text { combined }\end{array}$ \\
\hline $\begin{array}{l}\text { Incidence } \\
\text { Seasonal effect }\end{array}$ & $(\sqrt{ })$ & \\
Gender & & \\
Grade &
\end{tabular}

There seem to be no studies on the overall incidence and prevalence of injury of the extremities in the general population. However, a few studies have looked at children hospitalised or treated in emergency rooms. ${ }^{15-17}$ The present results are in accordance with Park et $a l^{19}$ when looking at four categories of upper extremity fractures in the whole population of South Korean children and adolescents from 0 to 18 years, where the highest incidence was observed in summer, followed in order by autumn, spring and winter. In the same study, the reverse was observed for two groups of lower extremity fractures, with peak fracture incidence in winter. ${ }^{19}$ Foltran et $a l^{15}$ who looked at all serious paediatric injuries in an Italian region found a clear seasonal variation in serious injuries, with distinct peaks in the prevalence of hospitalisation of seriously injured children in the summer, and a low prevalence during the winter. Graham et $a l^{16}$ also demonstrated this in a Scottish population of children with injuries needing emergency treatment. The very large retrospective study of Loder and Abrams ${ }^{17}$ was also in agreement with the present results.

Proposed explanations of the variation in number of injuries across seasons vary across a broad spectrum of potential extrinsic risk factors, including weather and playing surface, ${ }^{26-28}$ venue being indoor or outdoor ${ }^{11} 29$ and time of season. ${ }^{30}$ It also appears that the levels of physical activity vary with weather and season, thereby influencing the time-at-risk. ${ }^{31}$ Thus, several mechanisms can be at play, for example, the high injury incidence and prevalence in the autumn could have resulted from children starting organised sports participation without appropriate preparation. The results from the study of Wareham et $a l^{18}$ suggest that the overall physical activity and the use of outdoor recreational activities might be the significant factors as they found that children have a clear increased prevalence of wrist fractures in spring 
Figure 1 Fitted curves for seasonal variation for extremity injury incidence and prevalence, showing curves with regard to gender and grade level (0-6) as a proxy of age. The thick, solid line illustrates the mean curve. The dotted lines illustrate the period of 6 weeks of extrapolated data.
Figure 2 Fitted curves for seasonal variation for extremity injury incidence and prevalence, showing curves separately for lower extremity injuries with regard to gender and grade level $(0-6)$ as a proxy of age. The thick, solid line illustrates the mean curve. The dotted lines illustrate the period of 6 weeks of extrapolated data.
Girls

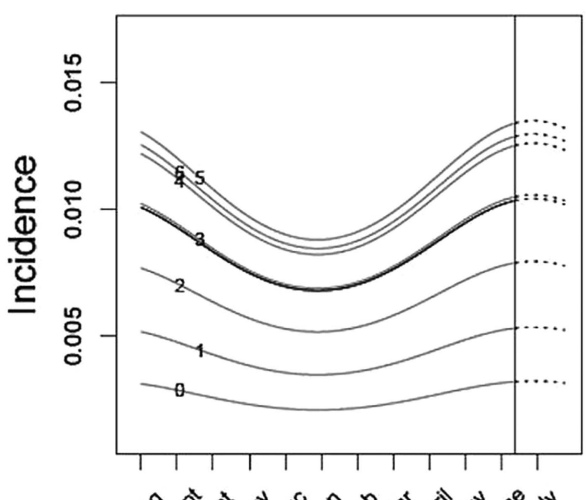

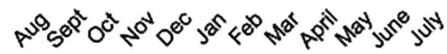

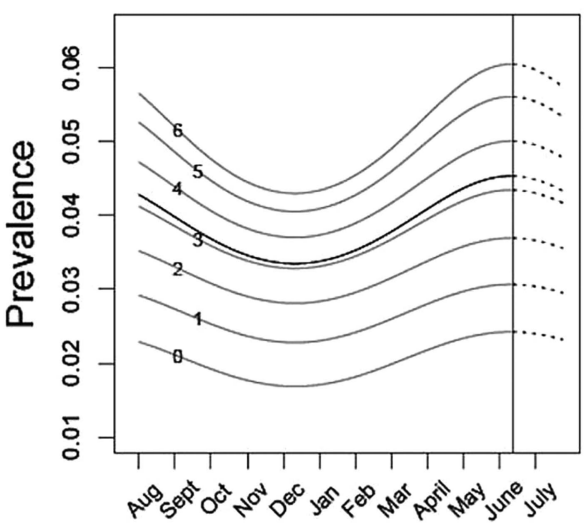

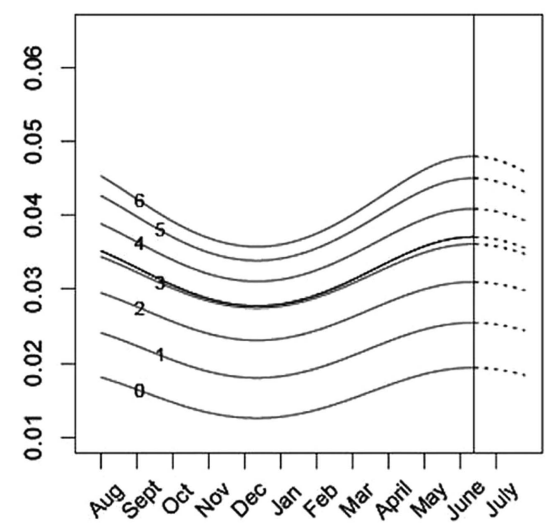

Boys
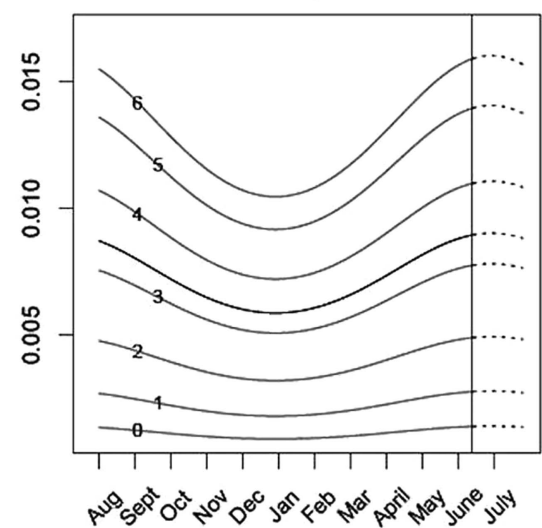

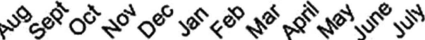

Girls

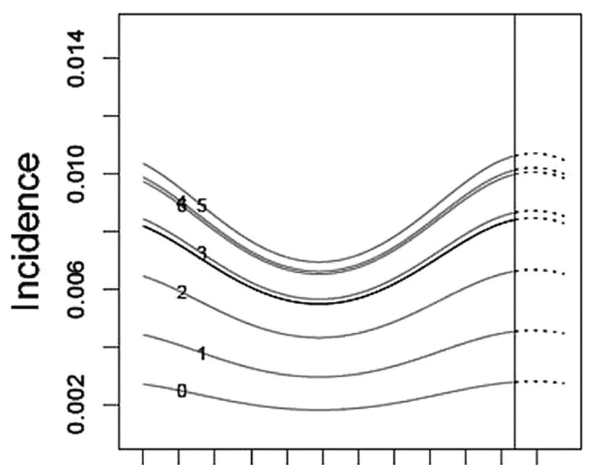

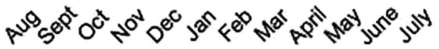

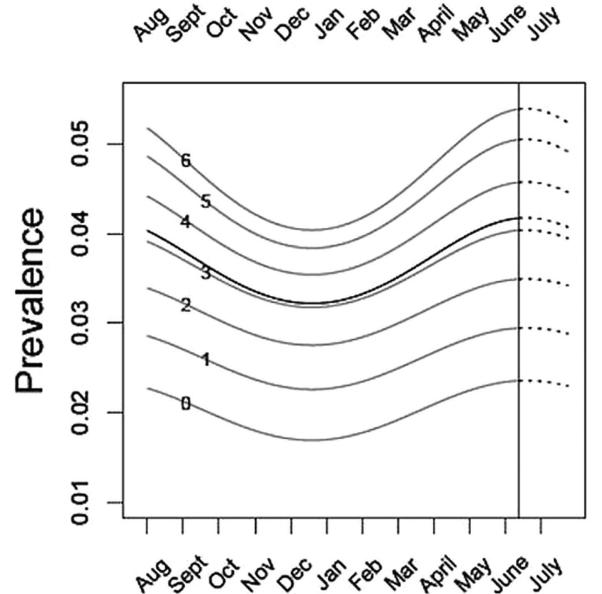

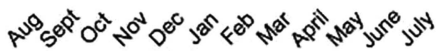
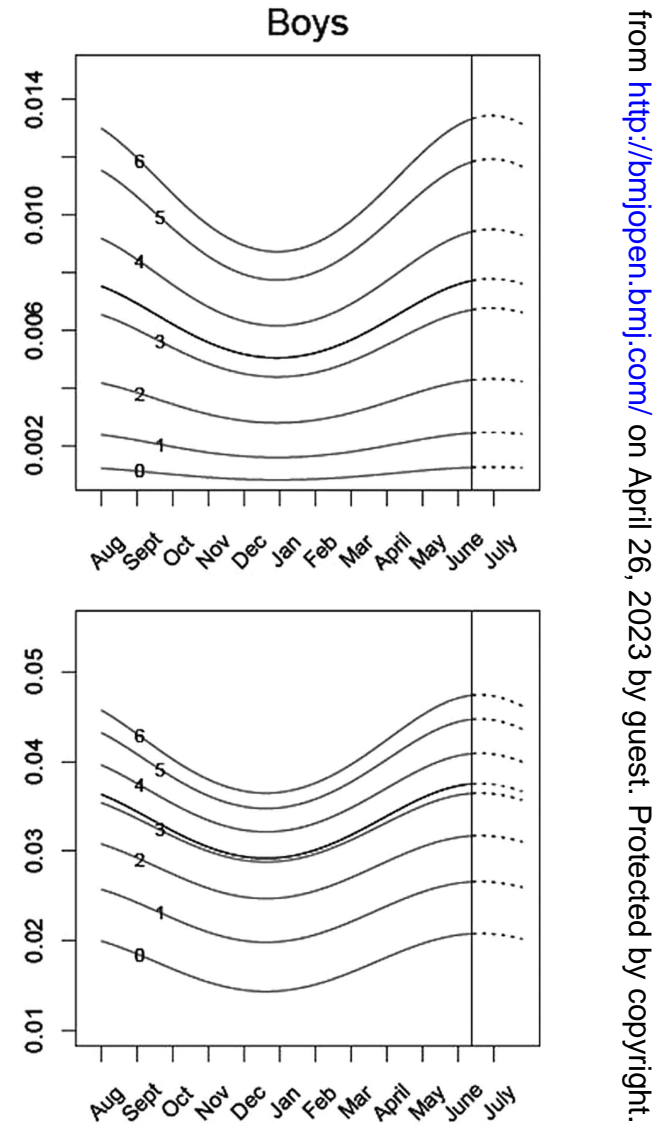
Figure 3 Fitted curves for seasonal variation for extremity injury incidence and prevalence, showing curves separately for upper extremity injuries with regard to gender and grade level (0-6) as a proxy of age. The thick, solid line illustrates the mean curve. The dotted lines illustrate the period of 6 weeks of extrapolated data.
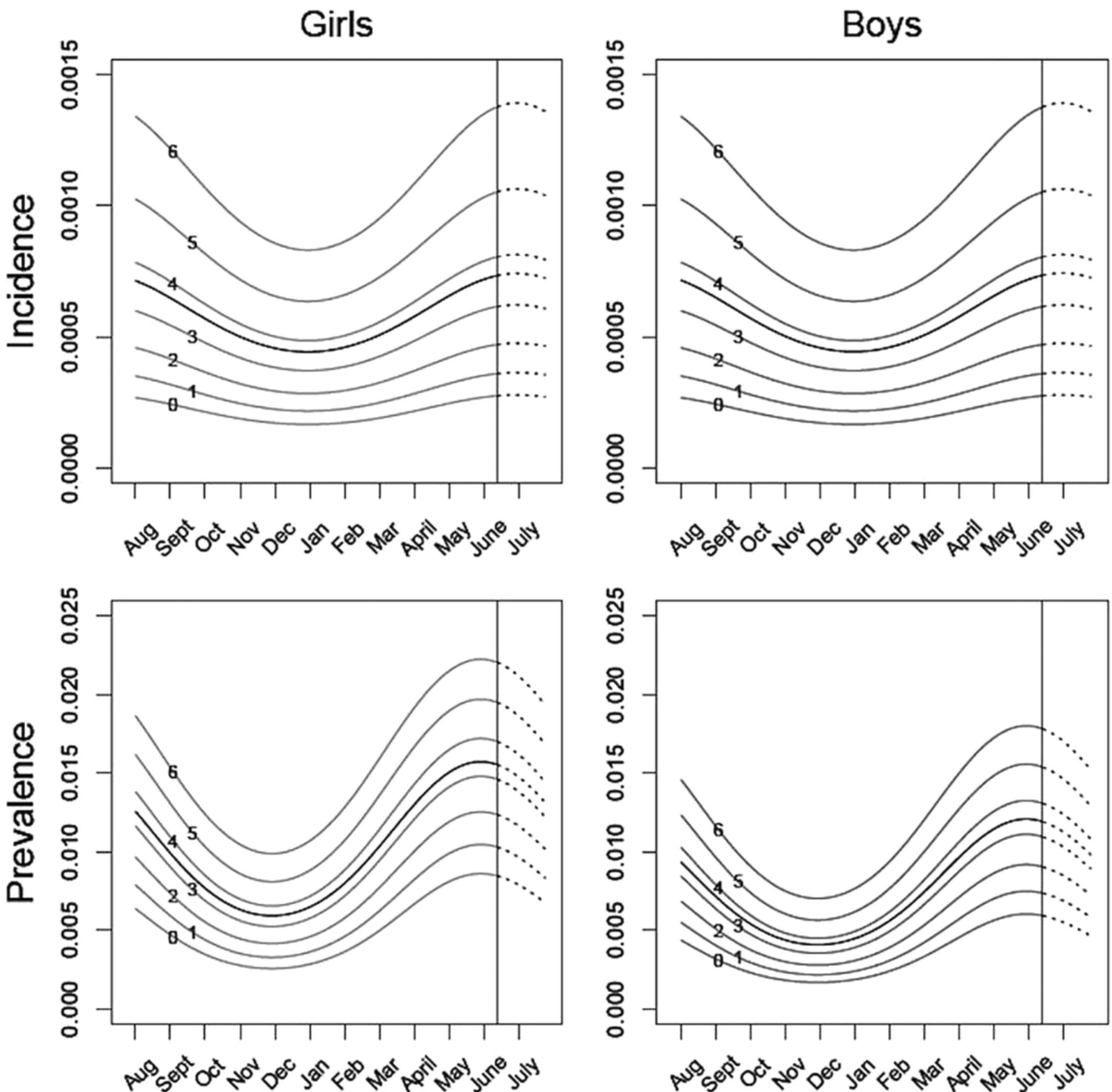

and summer. A Dutch school cohort study used a correction factor of 0.8 in order to account for the seasonal effects on physical activity participation throughout a 12-month follow-up period. ${ }^{13}$ Although arbitrarily chosen, the correction factor was in line with the decrease in physical activities during winter, found in a previous review study. ${ }^{31}$

The model-based estimates for seasonal variation showed a noticeable and surprising difference between the highest and lowest incidence and prevalence rates. A pattern was observed for the lowest prevalence rate early January preceding the lowest incidence rate 3 weeks later. Likewise, a pattern of the highest prevalence rate in late June was followed by the highest incidence rate 3 weeks later. Logically, high incidence rates should precede high prevalence rates and likewise with low rates. The prevalence of injury is the proportion of individuals who have an existing injury at any given point in time and is logically affected by the duration of injury. Injury durations vary, ${ }^{14}$ possibly reflecting different types of injuries and time for tissue to heal. It can be speculated that high prevalence rates at certain time points are the result of accumulated severe and long-lasting injuries and vice versa for low prevalence rates.

Looking at adjusted estimates, in the present study, all age groups followed the same pattern of seasonal variation for musculoskeletal extremity injury incidence and prevalence, but with more pronounced seasonal differences with increasing age. Risk of injury incidence consistently increases with age across most of the studies when looking at specific sports. ${ }^{32} 33$ This pattern was reproduced in this cohort of children with a broad diversity in choice of sports, amount of participation, competitive levels, etc. $^{14}$

The same patterns of higher injury incidence and prevalence estimates during warmer seasons than during winter were shown for both genders. A US study, analysing all paediatric emergency department visits during 4 years from seven selected activities (bicycles/tricycles, scooters, playground equipment, swimming/water activities, skiing/snowboarding, trampolines and skating activities) found different peaks for girls and boys (mean age 9.5 years). Girls had the highest number of emergency department visits in the spring and boys in the autumn. This were explained by the most common activity by gender peaking at the same time (girls=playground equipment activities, boys=cycling). ${ }^{17}$ The present study did not look at seasonal risk by specific activities, which might have disclosed the gender differences.

In this school-based cohort, approximately half of the children attended sports schools having three times as many physical education (PE) lessons as the rest of the children. This study has not taken the amount of 
physical activity into account, but it could still be speculated that the circumstances surrounding children being pupils at sports schools influences the injury risk. It is possible that not only the amount of PE lessons makes a difference, but also that the form and content of PE have a more pedagogic aim and are less competitive than sports participation in leisure time, thereby influencing the injury rates and the seasonal variation in injury risk.

Data collection was put on hold during 6 weeks of summer holidays, which is a limitation to this study. The predicted times of peak incidence and prevalence fall within this period. It seems, however, plausible to assume a consistent pattern all year round. Children being more physically active during the warmer season may likely explain the high rates of injuries at this time of the year. More activities take place outdoor, possibly under less rigorous supervision than during the winter indoor activities. In relation to injury prevention, attention should therefore be focused on outdoor activities and leisure time sport during this time of the year.

The registration method using weekly text messages resulted in a high response rate, strengthening this study. The high compliance is possibly explained by the benefit of parents having their children clinically examined if required. It could be argued that the frequent, prospective and sensitive monitoring potentially could result in a too high number of injuries. It was considered as a strength to this study that potential parental overreporting on pain and injuries was validated through objective examinations by clinicians before an injury was finally diagnosed. This fine-meshed method of recording all symptom-giving injuries has added a broader perspective to the area concerning musculoskeletal extremity injuries in children aged 6-12. Using SMS-Track to capture all symptoms indicative of musculoskeletal problems and subsequently having clinicians assigned to diagnose injuries, supplemented by data on injuries diagnosed in other clinical settings in the same time period, all ensure a larger probability of recording severe and less severe, traumatic and overuse injuries. Reporting of all injuries causing physical problems seems relevant in the case of the young, growing and playing child.

This study confirms the need to look into the dynamic and cyclic nature of risk factors and causation to understand injury aetiology. Risk factors are not stable, but may change through preceding cycles of exposure, circumstances and season as suggested by Meeuwisse et $a l^{34}$

\section{CONCLUSION}

There is a clear indication of a seasonal variation in musculoskeletal extremity injuries among children with almost twice as high injury incidence and prevalence estimates during autumn, summer and spring compared with winter.
Author affiliations

${ }^{1}$ Centre of Research in Childhood Health, Institute of Sports Science and Clinical Biomechanics, University of Southern Denmark, Odense, Denmark ${ }^{2}$ Department of Biostatistics, Institute of Regional Health Research, University of Southern Denmark, Odense, Denmark

${ }^{3}$ The Sport Medicine Clinic, Orthopaedic Department, Hospital of Lillebaelt, and Institute of Regional Health Service Research, University of Southern Denmark, Odense, Denmark

Acknowledgements The authors wish to acknowledge $\mathrm{K}$ Froberg and LB Andersen, Research in Childhood Health, University of Southern Denmark. The authors thank the participants and their parents and the participating schools, The Svendborg Project and the municipality of Svendborg. The authors also wish to thank Professor Charlotte Leboeuf-Yde for having assisted in drafting the manuscript, helped with the interpretation of data and revising the final manuscript. Finally, the authors wish to acknowledge the members of the Childhood Health, Activity, and Motor Performance School Study Denmark (CHAMPS Study-DK) not listed as co-authors of this article: H Klakk, M Heidemann, T Junge and NC Møller.

Contributors NW was responsible for the overall study concept and design. EJ, CTR, CF and NW were responsible for the acquisition of the data. EJ, RH and NW were responsible for the analysis and interpretation of data. EJ and NW drafted the manuscript. All authors took part in critical revision of the manuscript. RH provided statistical expertise.

Funding This study was supported by grants from The IMK Foundation, The Nordea Foundation, The TRYG Foundation-all private, non-profit organisations, which support research in health prevention and treatment, and TEAM Denmark, the elite sport organisation in Denmark, that provided the grant for the SMS-Track system.

Competing interests NW obtained the funding.

\section{Patient consent Obtained.}

Ethics approval The study was approved by the Ethics Committee for the region of Southern Denmark (ID S20080047).

Provenance and peer review Not commissioned; externally peer reviewed.

Data sharing statement The CHAMPS Study-DK is an on-going cohort study and results are being published continuously. Specific questions regarding data can be addressed by mailing EJ, ejespersen@health.sdu.dk or NW, Nwedderkopp@health.sdu.dk.

Open Access This is an Open Access article distributed in accordance with the Creative Commons Attribution Non Commercial (CC BY-NC 3.0) license, which permits others to distribute, remix, adapt, build upon this work noncommercially, and license their derivative works on different terms, provided the original work is properly cited and the use is non-commercial. See: http:// creativecommons.org/licenses/by-nc/3.0/

\section{REFERENCES}

1. Mikkelsson M, Salminen JJ, Kautiainen H. Non-specific musculoskeletal pain in preadolescents. Prevalence and 1-year persistence. Pain 1997;73:29-35.

2. El-Metwally A, Salminen JJ, Auvinen A, et al. Prognosis of non-specific musculoskeletal pain in preadolescents: a prospective 4-year follow-up study till adolescence. Pain 2004;110:550-9.

3. Brudvik C, Hove LM. Childhood fractures in Bergen, Norway: identifying high-risk groups and activities. J Pediatr Orthop 2003;23:629-34.

4. Conn JM, Annest JL, Gilchrist J. Sports and recreation related injury episodes in the US population, 1997-99. Inj Prev 2003;9:117-23.

5. Finch C, Valuri G, Ozanne-Smith J. Sport and active recreation injuries in Australia: evidence from emergency department presentations. Br J Sports Med 1998;32:220-5.

6. Collard DC, Verhagen EA, Chinapaw MJ, et al. Acute physical activity and sports injuries in children. Appl Physiol Nutr Metab 2008;33:393-401.

7. Collard DC, Verhagen EA, van Mechelen W, et al. Economic burden of physical activity-related injuries in Dutch children aged 10-12. Br J Sports Med 2011;45:1058-63. 
8. Kujala UM, Orava S, Parkkari J, et al. Sports career-related musculoskeletal injuries-long-term health effects on former athletes. Sports Med 2003;33:869-75.

9. Abernethy L, MacAuley D. Impact of school sports injury. Br J Sports Med 2003;37:354-5.

10. Oiestad BE, Holm I, Aune AK, et al. Knee function and prevalence of knee osteoarthritis after anterior cruciate ligament reconstruction: a prospective study with 10 to 15 years of follow-up. Am J Sports Med 2010;38:2201-10.

11. Backx FJ, Erich WB, Kemper AB, et al. Sports injuries in school-aged children. An epidemiologic study. Am J Sports Med 1989;17:234-40.

12. Sorensen L, Larsen SE, Rock ND. The epidemiology of sports injuries in school-aged children. Scand J Med Sci Sports 1996;6:281-6.

13. Verhagen $\mathrm{E}$, Collard $\mathrm{D}$, Paw MC, et al. A prospective cohort study on physical activity and sports-related injuries in 10-12-year-old children. Br J Sports Med 2009;43:1031-5.

14. Jespersen E, Holst R, Franz C, et al. Overuse and traumatic extremity injuries in schoolchildren surveyed with weekly text messages over 2.5 years. Scand J Med Sci Sports 2013. Epub ahead of print.

15. Foltran F, Avossa F, Fedeli U, et al. Seasonal variations in injury rates in children: evidence from a 10-year study in the Veneto Region, Italy. Int J Inj Contr Saf Promot 2012;20:254-8.

16. Graham CA, Macdonald A, Stevenson J. Children's injuries in a Scottish district general hospital. Injury 2005;36:1040-4.

17. Loder RT, Abrams S. Temporal variation in childhood injury from common recreational activities. Injury 2011;42:945-57.

18. Wareham K, Johansen $\mathrm{A}$, Stone MD, et al. Seasonal variation in the incidence of wrist and forearm fractures, and its consequences. Injury 2003;34:219-22.

19. Park MS, Chung CY, Choi IH, et al. Incidence patterns of pediatric and adolescent orthopaedic fractures according to age groups and seasons in South Korea: a population-based study. Clin Orthop Surg 2013;5:161-6.

20. Wedderkopp N, Jespersen E, Franz C, et al. Study protocol. The Childhood Health, Activity, and Motor Performance School Study Denmark (The CHAMPS-study DK). BMC Pediatr 2012;12:128.
21. SMS-Track. SMS-Track Aps. Esbjerg, Denmark. http://www. sms-track.com

22. Peterson L, Harbeck C, Moreno A. Measures of children's injuries: self-reported versus maternal-reported events with temporally proximal versus delayed reporting. J Pediatr Psychol 1993;18:133-47.

23. Kaalstad C, Tryti A. Ryggproblemer hos barn og kvaliteten av datainnsamling $i$ et epidemiologisk studie. Odense: University of Southern Denmark, 2011.

24. World Health Organization. International classification of diseases and health related problems (ICD-10), 10th revised edition. Geneva: WHO, 1992.

25. R Development Core Team R. A language and environment for statistical computing. Vienna, Austria: R Foundation for Statistical Computing, 2013.

26. Arnason A, Gudmundsson A, Dahl HA, et al. Soccer injuries in Iceland. Scand J Med Sci Sports 1996;6:40-5.

27. Meyers MC. Incidence, mechanisms, and severity of game-related college football injuries on FieldTurf versus natural grass: a 3-year prospective study. Am J Sports Med 2010;38:687-97.

28. Brophy $\mathrm{RH}$, Silvers HJ, Mandelbaum BR. Anterior cruciate ligament injuries: etiology and prevention. Sports Med Arthrosc 2010;18:2-11.

29. Emery CA, Meeuwisse WH. Risk factors for injury in indoor compared with outdoor adolescent soccer. Am J Sports Med 2006;34:1636-42.

30. Pinto M, Kuhn JE, Greenfield ML, et al. Prospective analysis of ice hockey injuries at the Junior A level over the course of one season. Clin J Sport Med 1999;9:70-4.

31. Tucker P, Gilliland J. The effect of season and weather on physical activity: a systematic review. Public Health 2007;121:909-22.

32. Emery CA. Risk factors for injury in child and adolescent sport: a systematic review of the literature. Clin J Sport Med 2003;13:256-68.

33. Caine D, Maffulli N, Caine C. Epidemiology of injury in child and adolescent sports: injury rates, risk factors, and prevention. Clin Sports Med 2008;27:19-50, vii.

34. Meeuwisse $\mathrm{WH}$, Tyreman $\mathrm{H}$, Hagel $\mathrm{B}$, et al. A dynamic model of etiology in sport injury: the recursive nature of risk and causation. Clin J Sport Med 2007;17:215-19. 